\title{
Desvelando dificuldades operacionais na sistematização da assistência de enfermagem na perspectiva da Grounded Theory*
}

Revealing operational difficulties in the systematization of nursing care from the Grounded Theory perspective

Descubriendo dificultades operacionales en la sistematización de la atención de enfermería en el enfoque de la Grounded Theory

Ana Lúcia Medeiros ${ }^{1}$, Sérgio Ribeiro dos Santos ${ }^{2}$, Rômulo Wanderley Lima Cabral ${ }^{3}$

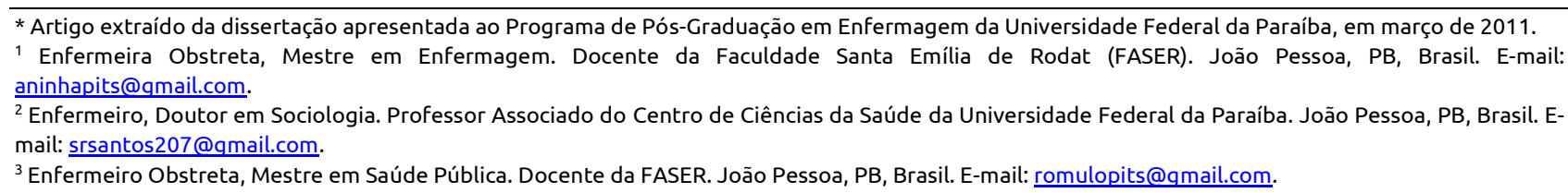

\section{RESUMO}

A Sistematização da Assistência de Enfermagem (SAE) aplicada por meio do processo de enfermagem representa uma metodologia fundamental no planejamento e execução dos cuidados de enfermagem. Este estudo teve como objetivo compreender os fatores que dificultam a operacionalização da SAE em um serviço de obstetrícia. Utilizaram-se o interacionismo simbólico e a grounded theory como referenciais teóricos e metodológicos. A população foi constituída por treze enfermeiros de uma maternidade pública, localizada na cidade de João Pessoa/Paraíba. Os enfermeiros foram entrevistados de acordo com os procedimentos de amostragem teórica. A análise dos dados resultou em dois fenômenos, o primeiro demonstra como os enfermeiros percebem a SAE e o segundo aponta fatores que dificultam a sua operacionalização. Conclui-se que os enfermeiros percebem a SAE como um instrumento de articulação teórico-prática que ainda apresenta muitos obstáculos na sua implementação, no entanto, reconhecem e indicam caminhos para maior adesão e êxito.

Descritores: Enfermagem; Processos de Enfermagem; Assistência de Enfermagem.

\section{ABSTRACT}

Nursing Care Systematization (NCS) applied by means of the nursing process is a fundamental methodology in planning and implementing nursing care. The objective of this study was to understand the factors that hinder NCS operationalization at an obstetric clinic. Symbolic interactionism and the grounded theory were used as the theoretical and methodological frameworks. The population consisted of thirteen nurses of a public maternity hospital, located in João Pessoa, Paraíba, Brazil. The nurses were interviewed according to the procedures of theoretical sampling. The data analysis resulted in two phenomena: the first demonstrates how nurses perceive NCS; and the second points at factors that hinder its operationalization. In conclusion, nurses perceive NCS as an instrument to connect theory and practice that still presents many obstacles to its implementation; however, they recognize and indicate paths to assure greater adherence and success.

Descriptors: Nursing; Nursing Process; Nursing Care.

\section{RESUMEN}

La Sistematización de Atención de Enfermería (SAE) aplicada mediante el proceso de enfermería representa una metodología fundamental de planificación y ejecución de cuidados de enfermería. Se apuntó a comprender los factores que dificultan la operacionalización de la SAE en un servicio de obstetricia. Se utilizó el interaccionismo simbólico y la grounded theory como referenciales teórico y metodológico. La población consistió en trece enfermeros de una maternidad pública, localizada en João Pessoa-Paraíba. Los enfermeros fueron entrevistados según procedimientos de muestreo teórico. El análisis de los datos resultó en dos fenómenos: uno demuestra cómo los enfermeros perciben a la SAE, el otro describe factores que dificultan su operacionalización. Se concluye en que los enfermeros perciben a la SAE como un instrumento de articulación teórico-práctica que aún presenta muchos obstáculos en su implementación; sin embargo, reconocen e indican caminos para mayor adhesión y éxito.

Descriptores: Enfermería; Procesos de Enfermería; Atención de Enfermería. 


\section{INTRODUÇÃO}

A enfermagem, ao longo de sua história como profissão, vem acompanhando as transformações ocorridas na sociedade. Isso tem exigido dos profissionais reflexões sobre o processo de cuidar do cliente, objetivando um cuidado que expresse um fazer de modo individualizado e metodologicamente sistematizado. Como resultado dessa reflexão, o cuidado passou a ter base num consistente conhecimento científico e na autonomia profissional $^{(1)}$.

A organização desse conhecimento ocorreu a partir de 1950, em consequência de um considerável avanço na construção e na organização dos modelos conceituais de enfermagem. Esses modelos foram desenvolvidos por diferentes caminhos, com conceitos comuns essenciais à prática profissional. Serviram como referencial para a elaboração das teorias de enfermagem, objetivando estabelecer uma relação entre diferentes conceitos, bem como melhor direcionar a assistência de enfermagem prestada ao ser humano(2).

Portanto, essas teorias subsidiaram a sistematização da assistência de enfermagem - SAE, de modo que sua aplicabilidade é feita por meio do processo de enfermagem, o qual promove cuidado humanizado, dirigido a resultados, que impulsiona o enfermeiro a examinar suas práticas, refletindo sobre maneiras de fazê-las melhor ${ }^{(3)}$.

No âmbito dessa reflexão, a SAE, reconhecido instrumento que favorece a organização do processo de cuidar, é tema atual das discussões da área, pois, apesar das diretrizes legais regulamentadas pela Resolução $n^{\circ}$ $358 / 2009$ do Conselho Federal de Enfermagem ${ }^{(4)}$, ainda são incipientes as experiências de sucesso.

Estudos desenvolvidos por enfermeiros nos últimos $\operatorname{anos}^{(5-6)}$ apontam diferentes dificuldades em sua implantação, dentre elas destacam-se: falta de conhecimento por parte do enfermeiro acerca da metodologia de assistência e modelos teóricos; deficiência na abordagem da temática durante o curso de graduação; grande demanda de serviços burocráticos e administrativos, além da falta de pessoal e de recursos materiais para o cuidado; falta de articulação entre a teoria e a prática; e, influências do modelo biomédico/cartesiano(7). São causas que representam, em sua maioria, problemas conceituais, estruturais e organizacionais.
Assim sendo, a prática diária tem demonstrado uma grande lacuna na aplicabilidade da SAE, evidenciada pelo de preenchimento incompleto do histórico de enfermagem; da falta de checagem das prescrições de enfermagem pelos técnicos; de reclamações de alguns enfermeiros alegando que não conhecem o funcionamento do processo de enfermagem. Assim sendo, pressupõe-se que a não utilização desse método, de uma forma integral e correta, origina uma assistência de enfermagem inadequada, não individualizada e não sistematizada.

Dessa forma, torna-se indispensável à discussão acerca dos resultados favoráveis e das dificuldades enfrentadas pelos enfermeiros para implantação da SAE. Nesse sentido, é importante que os modelos aplicados possibilitem um olhar mais abrangente do contexto e a participação mais efetiva da equipe de enfermagem e dos demais sujeitos envolvidos no processo, em especial, do próprio cliente enquanto sujeito ativo e participativo do processo de cuidar $^{(8)}$.

A partir desse contexto procurou-se resposta para os seguintes questionamentos: Como os enfermeiros do serviço de obstetrícia percebem a SAE? Que fatores dificultam sua operacionalização na prática destes profissionais?

Tais questões reforçam a importância do presente estudo, em face da necessidade de mudanças na assistência de enfermagem e do cumprimento das competências profissionais, das atribuições legais, dos fundamentos científicos e dos princípios que regem a profissão. Partindo desses pressupostos, o presente estudo teve como objetivo compreender os fatores que dificultam a operacionalização da SAE em um serviço de obstetrícia.

\section{METODOLOGIA}

Trata-se de um estudo descritivo, com abordagem qualitativa na perspectiva da grounded theory. Essa abordagem metodológica procura investigar os processos nos quais estão ocorrendo os fenômenos. Ela, inicialmente, busca uma fundamentação detalhada por meio dos dados coletados. Em seguida, realiza-se a análise sistemática dos dados, fazendo-se as comparações entre eles. Surge daí a teoria, que é vista como um processo em desenvolvimento e não como um produto acabado ${ }^{(9)}$. 
A pesquisa foi realizada em uma maternidade pública na cidade de João Pessoa, Paraíba, Brasil. A escolha do local se justifica, em virtude de ser a instituição reconhecida como centro de referência na formação de profissionais de enfermagem no Estado da Paraíba, na área de obstetrícia. Além disso, desenvolve o processo de enfermagem em seu serviço. Os sujeitos colaboradores da pesquisa foram os enfermeiros assistenciais que atuam no local onde a pesquisa foi realizada.

O número de enfermeiros que participaram do estudo não foi estabelecido, a priori, uma vez que o método de abordagem da grounded theory não adota uma amostragem estatística. Esta é determinada pelo propósito do estudo e pela relevância teórica, ou seja, o seu potencial para o desenvolvimento da teoria. Assim, à medida que os dados iam sendo coletados, eram submetidos à análise concomitante, visando à saturação teórica, a qual possibilitou o surgimento de possíveis grupos amostrais. A saturação da amostragem foi atingida após a realização da $13^{\mathrm{a}}$ entrevista.

Para a coleta dos dados, foram utilizadas as técnicas de observação participante e a entrevista semiestruturada, com questões norteadoras inerentes ao objetivo proposto na investigação. Quais sejam: Como você percebe a SAE? Em sua opinião, que fatores dificultam a aplicação do processo de enfermagem?

O convite para participação do estudo ocorreu após aprovação pelo Comitê de Ética em Pesquisa do Hospital Universitário Lauro Wanderley da UFPB (protocolo $n^{\circ}$ 083/10). Fizeram parte do estudo, enfermeiros que aceitaram participar voluntariamente, após serem devidamente informados a respeito do objetivo e assinarem o Termo de Consentimento Livre e Esclarecido, conforme estabelecido nas Diretrizes e Normas Regulamentadoras da Pesquisa Envolvendo Seres Humanos, constantes na Resolução n 196/96 do Conselho Nacional de Saúde.

Para que se pudesse compreender o significado dos dados obtidos com as entrevistas e as observações, procedeu-se a sua análise, codificando-os, categorizandoos e identificando a categoria central. A análise dos dados foi feita em três etapas interdependentes, denominadas de codificação aberta, codificação axial e codificação seletiva ${ }^{(9)}$.

A codificação aberta foi realizada manualmente, mediante leitura das entrevistas. Para cada fragmento da entrevista, foram atribuídas palavras ou expressões, formando os códigos preliminares. Na fase seguinte, atribuiu-se um nome conceitual ou abstrato para cada agrupamento de dados, código por código, que tinha alguma semelhança entre si ou mesmo características distintas. Os dados categorizados receberam a denominação de categorias, conforme foram interpretados.

Prosseguindo com a análise dos dados, passou-se à etapa da codificação axial, em que os dados foram agrupados em novas formas, estabelecendo as conexões entre as categorias, buscando expandir a teoria emergente. Dando continuidade ao processo analítico, passou-se para a etapa de codificação seletiva em que as categorias foram trabalhadas em profundidade e densidade de consistência. Esse processo de integração resultou em dois fenômenos distintos. Após a descrição analítica dos fenômenos, descobriu-se a categoria central que esteve presente na maioria dos relatos.

Quando essa etapa do trabalho foi atingida, buscouse inter-relacionar os fenômenos com as categorias representativas que traduzissem concretamente a sensibilidade teórica para compreender o significado da experiência dos enfermeiros como um todo. A partir daí, buscou-se desenvolver um modelo teórico representativo dessa experiência. O fenômeno foi examinado na perspectiva do paradigma de análise de Strauss e Corbin $^{(9)}$, como uma forma de agrupar as categorias e facilitar a análise dos dados. Para tanto, procurou-se entender quais eram as condições causais em que se desenvolviam o fenômeno, o contexto e as estratégias que estavam sendo conduzidas. Buscou-se também identificar as consequências que determinavam a ocorrência.

\section{RESULTADOS E DISCUSSÃO}

Participaram do estudo 13 enfermeiros, pertencentes às diferentes unidades de internação da instituição, com idade entre 20 e 50 anos, com mais de cinco anos de formação acadêmica e mais de três anos desenvolvendo suas atividades profissionais no serviço de obstetrícia. Dos participantes, a maioria nunca fez parte de programas de treinamento em relação a SAE.

A análise dos dados possibilitou realizar vários agrupamentos os quais resultaram em dois fenômenos que reúnem diversas categorias e subcategorias. Fazendo 
a conexão dos dois fenômenos, buscou-se integrar as categorias em relação ao contexto, às condições causais, às condições intervenientes, às estratégias de ação e às consequências, para assim identificar a categoria central, a qual é representada pelo processo: "Desvelando os fatores que dificultam a operacionalização da SAE, a partir da compreensão de que é um método de trabalho organizativo, capaz de direcionar o processo de enfermagem e promover a qualidade da assistência, autonomia, visibilidade e segurança"e pelo modelo teórico ilustrado na Figura 1.

Figura 1: Descobrindo a categoria central. João Pessoa, PB, 2011.
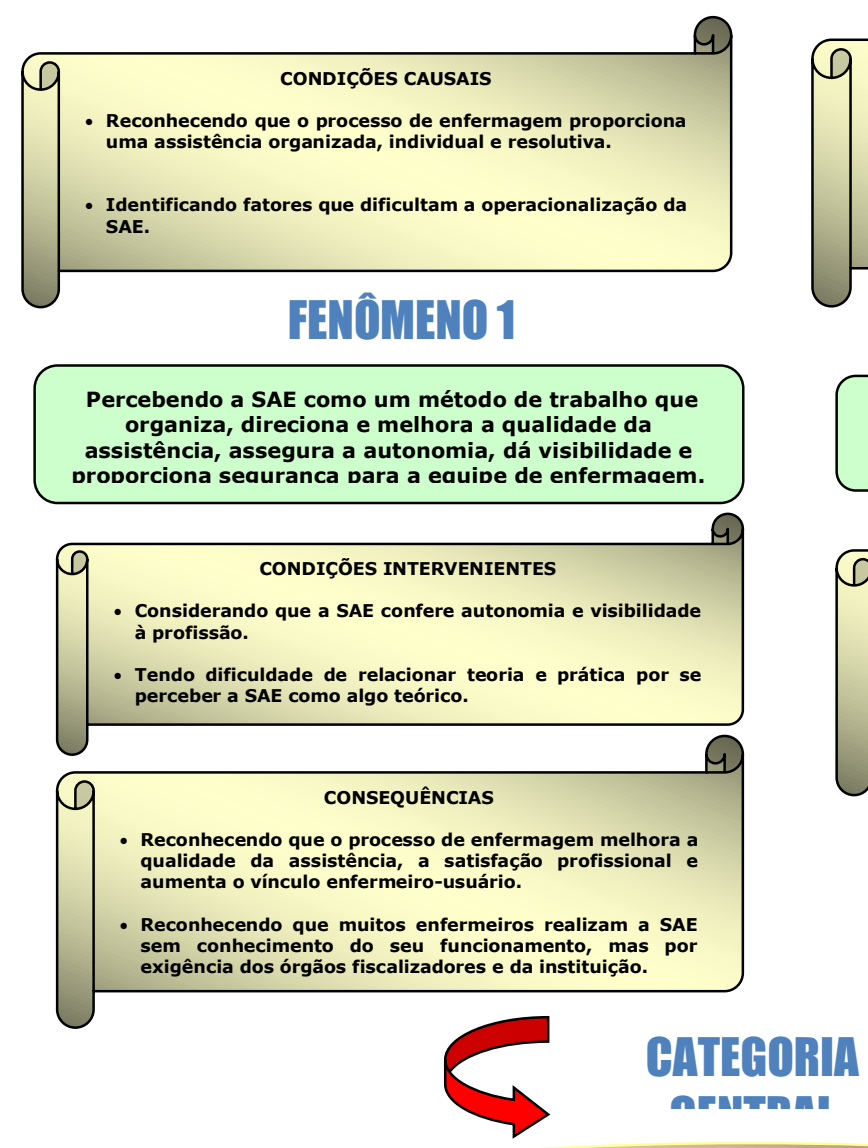

Superando os fatores que dificultam a operacionalização da SAE, a partir da compreensão de que é um método de trabalho organizativo, capaz de direcionar o processo de enfermagem, e promover a qualidade da assistência, autonomia, visibilidade e segurança.
A análise estabelecida a partir das conexões tomou por base a compreensão da experiência dos enfermeiros, bem como suas ligações e relações mútuas, a fim de se chegar à identificação da categoria central, que é a essência desse processo de integração.

\section{Descrevendo os Fenômenos}

Fenômeno 1: "Percebendo a SAE como um método de trabalho que organiza, direciona e melhora a qualidade da assistência, assegura a autonomia, dá visibilidade e proporciona segurança para a equipe de enfermagem". O modelo teórico que representa esse fenômeno está ilustrado na Figura 2. 
Figura 2: Modelo Teórico do Fenômeno 1. João Pessoa, PB, 2011.

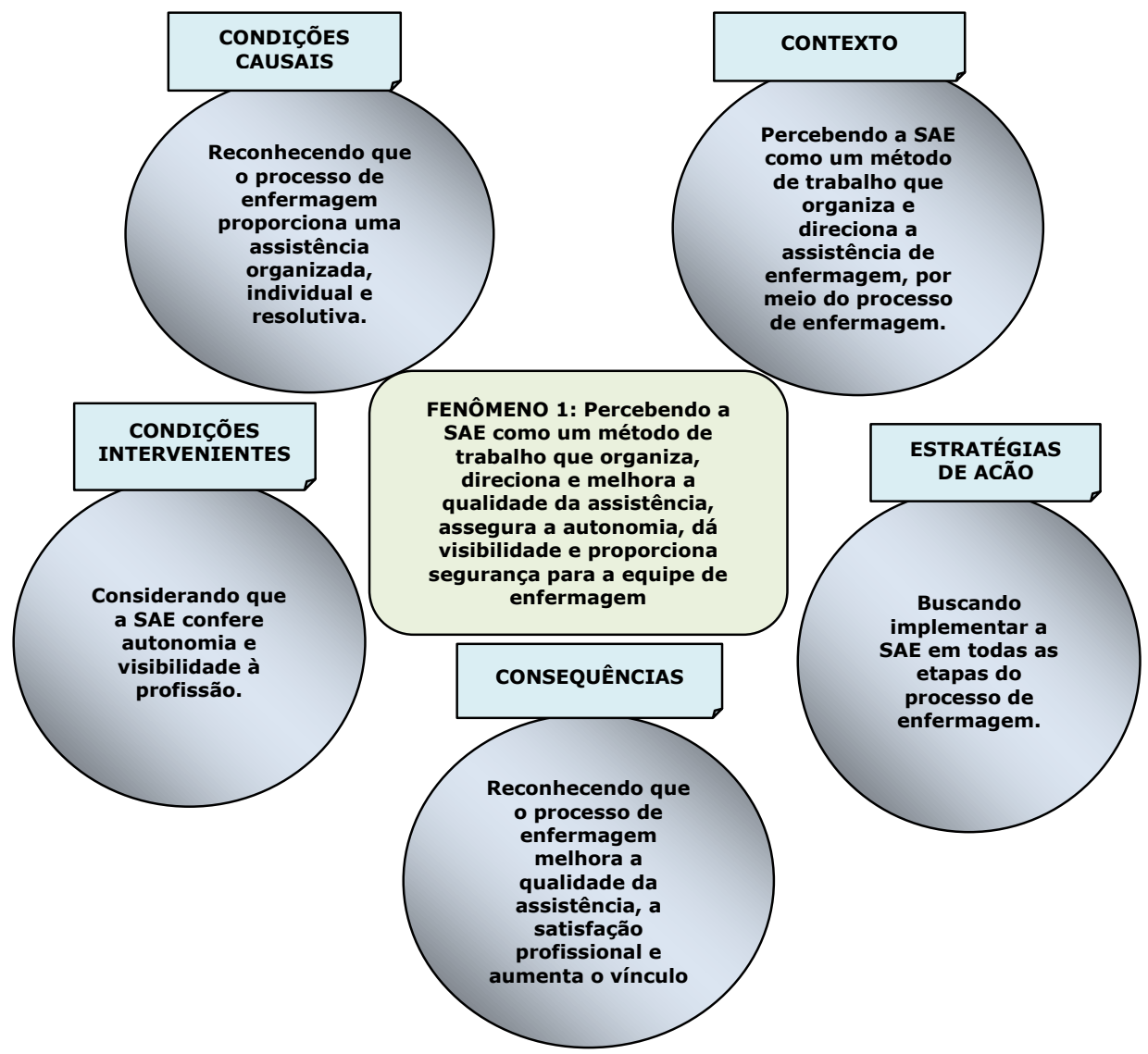

O Fenômeno 1 mostra que os enfermeiros percebem a SAE como uma metodologia de trabalho que organiza e direciona as ações de enfermagem, trazendo como resultado a melhoria da qualidade da assistência prestada, proporcionando mais autonomia, segurança e maior visibilidade à profissão. Enquanto processo de articulação teórico-prático, eles a entendem como um processo de qualificação profissional que propicia valorização, reconhecimento e otimização da assistência de enfermagem, conforme análise do fenômeno.

\section{A. Destacando as condições causais}

A categoria "reconhecendo que o processo de enfermagem proporciona uma assistência de enfermagem organizada, individual e resolutiva", mostra as causas que desencadeiam o fenômeno em questão.

Os enfermeiros reconhecem que a utilização da SAE direciona uma assistência voltada para as necessidades individuais, assim como, documenta suas ações de forma organizada, direcionando os cuidados prestados. Assim sendo, a utilização do processo de enfermagem vem trazendo à prática assistencial algumas vantagens, tais como: a abordagem holística do paciente, a obtenção de um corpo de conhecimento próprio, a busca por uma melhor qualidade da assistência e o favorecimento do aprimoramento contínuo do enfermeiro. Dessa forma, o enfermeiro, ao utilizar o processo de enfermagem com enfoque no diagnóstico, passa a ter subsídios para suas intervenções ${ }^{(10)}$.

Nesse cenário, percebe-se que o cliente é um ser autônomo, que interage com suas particularidades, devendo estas ser avaliadas no contexto da individualidade, considerando que ele está, a todo o momento, interagindo com o meio. Portanto, o enfermeiro deve aplicar o processo de enfermagem em um ciclo contínuo, dinâmico e individualizado, abrangendo a coleta de dados, o diagnóstico, o planejamento, a implementação e a avaliação na assistência de enfermagem ${ }^{(11)}$.

\section{B. Enfatizando o contexto}

A categoria "percebendo a SAE como um método de trabalho que organiza e direciona a assistência, por meio do processo de enfermagem", mostra o contexto onde a prática de enfermagem ocorre. Nesse aspecto, os enfermeiros percebem que a SAE é um método de 
trabalho que tem sustentação nos modelos teóricos aplicados à prática, através do processo de enfermagem, dando origem a uma metodologia de trabalho que sistematiza as ações e organiza o trabalho.

A SAE é uma metodologia de trabalho que direciona as práticas do cuidado, bem como organiza o fazer e o pensar do enfermeiro. Além disso, permite que seja ampliado o foco da assistência para todas as esferas do cuidar: físicas, espirituais, culturais, psicossociais, biológicas e emocionais, abordando não somente a patologia, mas também o indivíduo de maneira holística. Isso possibilita uma assistência orientada e, consequentemente, o aperfeiçoamento do ato de cuidar. A utilização do processo de enfermagem favorece a tomada de decisão do enfermeiro e proporciona segurança na prática clínica, assim como no desempenho de seu papel de trabalhar em equipe ${ }^{(12)}$.

\section{Destacando as condições intervenientes}

A categoria que representa as condições intervenientes do fenômeno 1 é: "Considerando que a SAE confere autonomia e visibilidade à profissão". Essa categoria mostra os aspectos que corroboram o impacto das condições que intervêm no fenômeno.

Os enfermeiros consideram que a SAE confere autonomia profissional, desde que toda a equipe de enfermagem passe a utilizar essa metodologia de trabalho em suas ações, por meio da aplicação sistemática do processo de enfermagem. É inegável que um cuidado de enfermagem sistematizado, alicerçado nos referenciais técnico-científicos, promove a valorização da categoria. Destarte, o enfermeiro passará a conquistar seu espaço por méritos, tendo a certeza de que suas práticas trarão contribuições ao paciente ${ }^{(13)}$.

Portanto, é bom lembrar que a autonomia profissional da enfermagem só será alcançada, através de conhecimentos técnico-científicos, de atividades legais e, primordialmente, do desenvolvimento de uma prática humanizada. A elevação da autoestima dos profissionais de enfermagem, obtida através da utilização da SAE, expressa a confiança no próprio potencial, a certeza da capacidade de enfrentar os desafios da profissão e a consciência do próprio valor da busca do sucesso profissional.

\section{Desenvolvendo estratégias de ação}

Para que a SAE se apresente como um método de trabalho que organiza e direciona as ações da enfermagem, melhorando a qualidade da assistência prestada, trazendo autonomia e visibilidade à profissão, os enfermeiros do serviço onde a pesquisa foi realizada, desenvolvem a seguinte estratégia de ação: "buscando implementar a SAE em todas as etapas do processo de enfermagem".

O processo de enfermagem se operacionaliza em fases, que variam de acordo com cada autor no que diz respeito ao número e à terminologia utilizada. No serviço onde a pesquisa foi realizada, o processo de enfermagem é constituído de cinco fases, a saber: coleta de dados, diagnósticos de enfermagem, planejamento da assistência, implementação e avaliação da assistência de enfermagem.

Por ter origem nas práticas da enfermagem, o processo de enfermagem possui suas fases interdependentes e complementares. Quando realizadas concomitantemente, resultam em intervenções satisfatórias para o cliente.

Рara que o enfermeiro possa garantir excelência no desempenho de suas funções, ele utiliza o processo de enfermagem no dia-a-dia, contribuindo para a construção de competências, condição imprescindível para a produção, evolução e inovação do conhecimento. Por essa razão, deve-se valorizar a assistência, o ensino e a pesquisa.

\section{E. Identificando as consequências do fenômeno}

A categoria "reconhecendo que o processo de enfermagem melhora a qualidade da assistência, a satisfação profissional e aumenta o vínculo enfermeirousuário" mostra as consequências do fenômeno em estudo identificadas pelos enfermeiros.

O processo de enfermagem deve ser constituído por um modelo assistencial que poderá ser aplicado em todas as áreas de assistência de enfermagem, inclusive na obstetrícia. Seu objetivo é melhorar a qualidade da assistência e gerar maior satisfação profissional, aumentando o vínculo entre o enfermeiro e o usuário.

Portanto, o processo de enfermagem é uma estratégia que possibilita o desenvolvimento de relações humanizadas por causa do vínculo criado entre enfermeiros e usuários. O significado da humanização compreende o olhar ampliado para as necessidades de 
saúde dos usuários, considerando os aspectos biopsicossociais e o contexto de vida das pessoas. Abrange também o respeito aos princípios éticos, tais como o respeito pelo outro, a dignidade e a autonomia, facilitando, com isso, o acesso aos serviços de saúde ${ }^{(14)}$.
Fenômeno 2: "Apontando fatores que dificultam a operacionalização da SAE e os caminhos para maior adesão e êxito, por meio da aplicação do processo de enfermagem". O modelo teórico que representa esse fenômeno está ilustrado na Figura 3.

Figura 3: Modelo teórico do fenômeno 2. João Pessoa, PB, 2011.

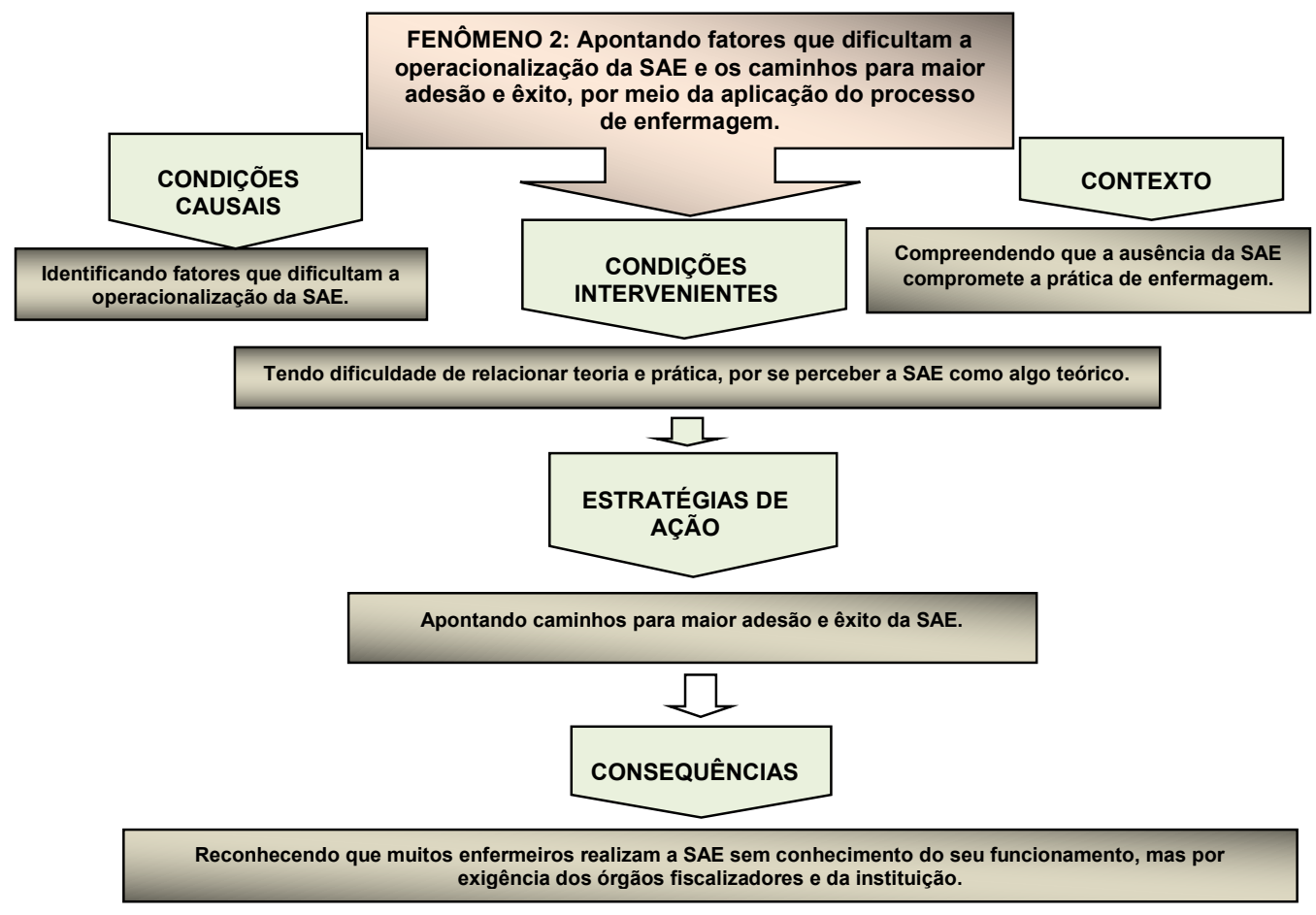

No cenário da saúde, a prática do enfermeiro está baseada em cuidados de enfermagem respaldados numa base teórico-científica sustentada na SAE e aplicada através do processo de enfermagem.

No entanto, a operacionalização do processo de enfermagem tem esbarrado em muitos fatores que dificultam sua aplicação na prática diária do enfermeiro. Alguns desses fatores estão no âmbito da organização (políticas, normas, objetivos dos serviços), muitas vezes, estabelecidos por outros profissionais e administradores sem a participação dos enfermeiros. Outros fatores fazem parte do quotidiano desses profissionais (atitudes, crenças, valores, habilidades técnicas e intelectuais), para os quais muitas vezes se busca explicação nas deficiências do ensino formal e na sua relação com a prática. Outro fator é a maneira como o processo tem sido operacionalizado nos serviços, por exemplo, uma imposição da chefia de enfermagem que valoriza mais a documentação do que a implementação efetiva dessa metodologia(15).
Рara identificar os fatores que dificultam a operacionalização da SAE e os caminhos para seu êxito, tornou-se necessária a análise das atividades dos enfermeiros, através de depoimentos e observações de suas práticas no dia-a-dia. A análise possibilitou desenhar o modelo teórico desse fenômeno, representado na Figura 3.

No cenário da saúde, a prática do enfermeiro está baseada em cuidados de enfermagem respaldados numa base teórico-científica sustentada na SAE e aplicada através do processo de enfermagem.

No entanto, a operacionalização do processo de enfermagem tem esbarrado em muitos fatores que dificultam sua aplicação na prática diária do enfermeiro. Alguns desses fatores estão no âmbito da organização (políticas, normas, objetivos dos serviços), muitas vezes, estabelecidos por outros profissionais e administradores sem a participação dos enfermeiros. Outros fatores fazem parte do quotidiano desses profissionais (atitudes, crenças, valores, habilidades técnicas e intelectuais), рага 
os quais muitas vezes se busca explicação nas deficiências do ensino formal e na sua relação com a prática. Outro fator é a maneira como o processo tem sido operacionalizado nos serviços, por exemplo, uma imposição da chefia de enfermagem que valoriza mais a documentação do que a implementação efetiva dessa metodologia(16).

Рага identificar os fatores que dificultam a operacionalização da SAE e os caminhos para seu êxito, tornou-se necessária a análise das atividades dos enfermeiros, a partir dos depoimentos e observações de suas práticas no dia-a-dia.

\section{A. Destacando as condições causais}

A categoria "identificando fatores que dificultam a operacionalização da $S A E^{\prime \prime}$ mostra as causas que desencadeiam o fenômeno em estudo. São consideradas causais porque os enfermeiros apontaram os principais fatores que interferem na operacionalização da SAE, prejudicando a sua implementação. Eles tentaram mostrar o que, na prática, tem contribuído para a não realização da SAE. E assim, esperam que surjam propostas de soluções que contribuam para sua viabilização, de modo a aprimorar essa metodologia de trabalho da enfermagem.

Segundo apontou essa categoria, as dificuldades enfrentadas pelos enfermeiros para implantação da SAE são diversas, destacando-se as seguintes: o número reduzido de profissionais de enfermagem, a falta de credibilidade dos técnicos de enfermagem frente à $S A E$, as questões políticas, o desconhecimento dos enfermeiros quanto às prescrições de enfermagem, a sobrecarga de trabalho do enfermeiro, o tempo, a pouca vontade dos gestores em implantar a SAE, o desconhecimento do funcionamento do processo e a falta de motivação profissional.

\section{B. Enfatizando o contexto}

A categoria "compreendendo que a ausência da $S A E$ compromete a prática de enfermagem", explica o contexto da prática dos enfermeiros, ou seja, mostra que eles têm consciência da importância da SAE na sua prática diária.

Uma das características da enfermagem moderna é a utilização da SAE na implementação do processo de enfermagem. Ela representa uma conquista para os profissionais e para os clientes, refletindo na prestação de cuidados individuais e centrados nas necessidades. Além disso, norteia a tomada de decisões em diversas situações vivenciadas pelo enfermeiro, enquanto gerenciador da equipe de enfermagem.

Logo, a não utilização da SAE pode trazer muitas consequências. $O$ principal problema é o comprometimento da qualidade da assistência prestada, refletindo no desconhecimento das necessidades do cliente. Outras consequências são: a desorganização do serviço gerada pelas diferentes formas de conduta profissional na assistência; o conflito vivenciado entre o desejo de prestar uma assistência direta ao cliente e as atividades administrativas; a desvalorização do enfermeiro no ambiente hospitalar; o desgaste de recursos humanos evidenciados pela falta de planejamento, resultando na diminuição da produtividade e da qualidade dos cuidados; a perda de tempo gerada pela ausência de planejamento e determinação de prioridades ${ }^{(17)}$.

\section{Destacando as condições intervenientes}

A categoria que revela aspectos que fortalecem ou atenuam o impacto das condições intervenientes no fenômeno em estudo é "tendo dificuldade de relacionar teoria e prática, por se perceber a SAE como algo teórico". $\mathrm{Na}$ percepção de alguns enfermeiros, existem dificuldades de relacionar a teoria à prática, quando se trata de SAE. Muitos deles têm dificuldade de operacionalizá-la, por considerarem uma atividade teórica, que se encontra apenas no papel, muito distante da realidade. Nesse aspecto, os enfermeiros mostram que há uma fragilidade no caminho da implementação da SAE, em decorrência do surgimento de muitos problemas. Portanto, essas dificuldades precisam ser compreendidas para que se criem estratégias que possam ajudar na sua superação, de modo que os enfermeiros consigam desenvolver uma assistência planejada e organizada.

A falta de relação entre teoria e prática em enfermagem existe como resultado do processo de formação desses profissionais que normalmente é realizado dentro de uma estrutura teórica pouco adequada para a prática de enfermagem. Por conseguinte, o modelo acadêmico que prevalece no preparo dos enfermeiros ainda é o técnico-racional, que descreve uma perspectiva científica da enfermagem 
como um conhecimento hierárquico, teórico e de status $\operatorname{acadêmico}^{(18)}$.

\section{Desenvolvendo estratégias de ação}

A visão dos enfermeiros frente à experiência vivenciada na prática está voltada para a SAE como um caminho para a construção de um conhecimento integrado (explícito ou tácito). Diante da possibilidade de melhorar a operacionalização da SAE, o estudo apresenta a seguinte estratégia de ação: "apontando caminhos para maior adesão e êxito da SAE".

Os enfermeiros do serviço apontaram alguns caminhos que facilitam a efetividade da SAE, como treinamentos da equipe de enfermagem, vontade política dos administradores, dedicação dos enfermeiros, uso de instrumentos que contemplem as fases do processo de enfermagem e maior divulgação do processo, garantindo a adesão e êxito na prática da enfermagem.

É importante entender que a divulgação é o meio que oferece a possibilidade de reconhecimento das melhorias advindas da utilização da SAE, abrindo caminhos para a pesquisa e para a reflexão em busca de alternativas para a melhoria da prática de enfermagem.

\section{E. Identificando as consequências do fenômeno}

Diante da possibilidade de se criarem novas condições para a implementação da SAE, o estudo apresenta a seguinte categoria: "reconhecendo que muitos enfermeiros realizam a SAE sem conhecimento do seu funcionamento, mas apenas por exigência dos órgãos fiscalizadores e da instituição". Essa categoria mostra as consequências do fenômeno identificadas pelos enfermeiros.

Embora a SAE tenha sido implantada no Brasil desde a década de 1970, só recebeu apoio legal do Conselho Federal de Enfermagem em 2002, por meio da Resolução $n^{\circ} 272 / 02^{(19)}$ e, em seguida, pela Resolução no 358/09(4). Entretanto, muitas pesquisas mostram que essas Resoluções não foram suficientes para orientar sua implantação, já que muitas dificuldades ainda são encontradas para a realização dessa metodologia assistencial.

Nesse sentido, alguns estudos mostram que a identificação dos diagnósticos e a elaboração das prescrições são consideradas, pela maioria dos enfermeiros, como as maiores dificuldades para a aplicabilidade e efetivação da $\mathrm{SAE}^{(15-16)}$. Outros estudos demonstraram que o tempo consumido com 0 preenchimento e manuseio dos formulários do processo de enfermagem têm sido um grande obstáculo(12,20).

Nesse cenário, os enfermeiros do serviço de obstetrícia reconhecem que muitos profissionais de enfermagem realizam a SAE apenas por exigências do COREN e da própria instituição onde trabalham, não reconhecendo os benefícios que ela pode trazer para o cliente, para a instituição e, principalmente, para a enfermagem.

\section{CONSIDERAÇÕES FINAIS}

Os enfermeiros reconhecem o processo de enfermagem como um método de articulação teóricoprático, que direciona uma assistência voltada para as necessidades individuais, auxiliando a sua resolução; documenta as ações de enfermagem de forma organizada, direcionando os cuidados prestados; proporciona segurança ao cliente em relação à assistência prestada, bem como à equipe de enfermagem, porque as orientações são registradas no prontuário; facilita a continuidade da assistência, gerando satisfação e reconhecimento profissional, aumentando o vínculo enfermeiro-usuário. Desta forma, eles consideram o processo de enfermagem como um processo decisório, que norteia o raciocínio do enfermeiro no planejamento da assistência de enfermagem.

O estudo evidenciou que entre tantos fatores que têm dificultado a operacionalização da SAE no serviço de obstetrícia, apontados pelos enfermeiros, merece destaque a falta de credibilidade dos técnicos de enfermagem frente à SAE, a sobrecarga de trabalho do enfermeiro, a pouca vontade dos gestores em implantá-la e o desconhecimento do funcionamento do processo pelos profissionais de enfermagem.

A integração das categorias emergida do estudo, mostrou que os enfermeiros demonstraram interesse em buscar alternativas para enfrentar as dificuldades, traçando os caminhos para sua maior adesão, no sentido de implementar a SAE em todas as etapas do processo de enfermagem para que as necessidades da clientela pudessem ser atendidas com qualidade. 


\section{REFERÊNCIAS}

1. Vasconcelos $C P$, Boaventura PP, Lima LM, Volpe CRG, Funghetto SS, Stival MM. Nurses' knowledge about systematization of nursing assistance. Rev enferm UFPE on line. [Internet]. 2011 [acesso em: 29 mar 2013]; 5(1):10-9. Disponível em:

http://www.ufpe.br/revistaenfermagem/index.php/revista/artic le/view/1137/pdf 271.

2. Nóbrega MML, Silva KL. Fundamentos do cuidar em enfermagem. Belo Horizonte: ABEn; 2009.

3. Amante LN, Rossetto AP, Schneider DG. Sistematização da Assistência de Enfermagem em Unidade de Terapia Intensiva sustentada pela Teoria de Wanda Horta. Rev Esc Enferm USP On line. [Internet]. 2009 [acesso em: 29 mar 2013]; 43(1):54-64. Disponível em: http://www.scielo.br/pdf/reeusp/v43n1/07.pdf 4. COFEN. Resolução $n^{\circ} 358$, de 15 de outubro de 2009. Dispõe sobre SAE e a implementação do processo de enfermagem em ambientes, públicos ou privados, em que ocorre o cuidado profissional de enfermagem. Rio de Janeiro: COFEN; 2009. 5. Lanssoni FZ, Fonseca MRCC, Osinaga VLM. A Sistematização da Assistência de Enfermagem (SAE): dificuldades para sua implantação e operacionalização. $16^{\circ}$ Congresso de Iniciação Científica. Ciência, Tecnologia e Sociedade: responsabilidade social. Piracicaba/SP; 2008.

6. Gonçalves LRR, Nery IS, Nogueira LT, Bonfim EG. O desafio de implantar a sistematização da assistência de enfermagem sob a ótica de discentes. Esc Anna Nery Rev Enferm. [Internet]. 2007 [acesso em: 29 mar 2013];11(3):459-65. Disponível em: http://www.scielo.br/pdf/ean/v11n3/v11n3a10.pdf. 7. Fuly PSC, Leite JL, Lima SBS. Correntes de pensamento nacionais sobre sistematização da assistência de enfermagem. Rev Bras Enferm. 2008; 61(6):883-7.

8. Silva MM, Moreira MC. Desafios à sistematização da assistência de enfermagem em cuidados paliativos oncológicos: uma perspectiva da complexidade. Rev Eletr Enf [Internet]. 2010 [acesso em: 29 mar 2013];12(3):483-90. Disponível em: http://www.fen.ufg.br/revista/v12/n3/v12n3a10.htm. 9. Strauss A, Corbin J. Pesquisa qualitativa: técnica e procedimentos para o desenvolvimento da teoria fundamentada. 2 ed. Porto Alegre: Artmed; 2008. 10. Queiroz OCA, Sant'Ana RSE, Oliveira SC, Moinhos AS, Santos LS. Nurse's perception in front of the implementation of nursing diagnosis and prescription. Rev enferm UFPE on line. [Internet]. 2012 [acesso em: 29 mar 2013]; 6(6):1346-515. Disponível em: http://www.ufpe.br/revistaenfermagem/index.php/revista/artic le/view/2617/pdf 1238.

11. Tannure MC, Chianca TCM. A seleção do referencial teórico de Orem para a sistematização da assistência de enfermagem. Rev Nursing. 2006;100(8):1004-9.

12. Remizoski J, Rocha MM, Vall J. Dificuldades na implantação da assistência de enfermagem - SAE: uma revisão teórica. Caderno da Escola de Saúde. 2010;3(1):1-14.

13. Oliveira SCC, Oliveira FCC, Alves TEA, Soares FRR, Cavalcanti JRLP. A assistência de enfermagem às vítimas com traumatismo cranioencefálico: rediscutindo as práticas emergenciais. Rev enferm UFPE on line. [Internet]. 2011 [acesso em: 29 mar 2013];(10):2415-19. Disponível em:

http://www.revista.ufpe.br/revistaenfermagem/index. php/revista/article/viewFile/2460/pdf 1208.

14. Moura FMJSP, Crizostomo CD, Nery IS, Mendonça RCM, Araújo OD, Rocha SS. A humanização e a assistência de enfermagem ao parto normal. Rev Bras Enferm. 2007; 60(4):452-5.

15. Carvalho EC, Bachion MM, Dalri MCB, Jesus CAC. Obstáculos para a implementação do processo de enfermagem no Brasil. Rev enferm UFPE on line. [Internet]. 2007 [acesso em: 29 mar 2013]; 1(1):95-99. Disponível em: http://www.revista.ufpe.br/revista
enfermagem/index.php/revista/article/viewFile/17-8781-1Lpdf 172

16. Pokorski S, Moraes MA, Chiarelli R, Costanzi AP, Rabelo ER. Processo de enfermagem: da literatura à prática. $O$ que de fato nós estamos fazendo? Rev latinoam enferm. 2009;17(3):302-7. 17. Andrade JS, Vieira MJ. Prática assistencial de enfermagem: problemas, perspectivas e necessidade de sistematização. Rev Bras Enferm. 2005;58(3):261-5.

18. Santos SR, Nóbrega MML. A busca da interação teoria e prática no sistema de informação em enfermagem - enfoque na teoria fundamentada nos dados. Rev latinoam enferm. 2005;3(12):460-8.

19. Conselho Federal de Enfermagem (COFEN). Resolução $n^{\circ}$ 272 , de 27 de agosto de 2002. Dispõe sobre a sistematização da assistência de enfermagem nas instituições de saúde. Rio de Janeiro: COFEN; 2002.

20. Gonçalves LRR, Nery IS, Nogueira LT, Bonfim EG. O desafio de implantar a sistematização da assistência de enfermagem sob a ótica de discente. Esc. Anna Nery Rev. Enferm. 2007;11(3):459-65.

Artigo recebido em 15/08/2011. Aprovado para publicação em 05/09/2012. Artigo publicado em 31/03/2013. 